\title{
FOREST BOUNDARIES IN BRITISH COLUMBIA
}

\author{
F. D. MulHolland \\ British Columbia Forest Service.
}

$\mathrm{T}^{\mathrm{H}}$

$\mathrm{HE}$ word forest is changing its meaning in British Columbia as it has done in older countries. Not quickly, because the population increase is slow, and the wooded area is still so vast that its reduction is not too obvious. But it is changing. One generation ago the forest seemed ubiquitous and inexhaustible. It was an enemy to the pioneer who wished to till the soil, graze his stock, prospect for gold. Though he built with logs and sold a few ship spars, there was too much of it; it was all outdoors; it got in his way; so he burned it. There were no special forest laws and little forest revenue; in 1900 only $\$ 142,000$.

Markets developed; saw and pulp mills were built; timber was sold (but not forest land); the forest became of economic importance instead of just a place to hunt, trap, and fish. By 1930 forest revenue was three and a half million dollars. British Columbia begins to adopt a rational and systematic treatment of its forests, like other civilized countries. The word forest begins to mean a place most suitable for the production of timber of commercial value.

With this definition of a forest accepted, the necessity for many administrative steps becomes obvious to a forester. But unless the forests are distinguished in some way from other classes of land, administration designed for forests will necessarily be dissipated and become less effective. Unfortunately this kind of forest in British Columbia is not usually provided by nature with definite boundaries. As it climbs the mountains it shades gradually into the alpine parks and stunted trees growing on the highland pastures; on the low lands it dwindles into the scattered stands and lone trees of the grass ranges or merges with insignificant scrub on soils too poor to produce merchantable trees. Also the best soils are wanted for agriculture, they too must be eliminated from consideration as forest. Other than sea coast and lake shore, boundaries for commercial forests must usually be set by man.

With the setting aside of Provincial Forests for the perpetual production of timber British Columbia has taken the first step towards recognition of the forest as a permanent locale for the occupation of many of its citizens. These Forests now include 8,500,000 acres. Their capacity for sustained annual yield is estimated to be 355 million f.b.m. This will increase when forest management has had time to take effect, but as British Columbia has been producing between two and three billion feet per annum for some years there is still a long way to go before its forest industries are assured of an adequate yearly supply of timber from regulated forests. 
As each area of forest land is dedicated to forestry in British Columbia a survey is made of it and its boundaries are delineated so far as possible in such a way as to make it an administrative unit. Also to minimize the confusion and waste of effort caused by temporary allocation of land for a purpose for which its use must be permanent in order to be successful.

The difficulties to be overcome in locating permanent boundaries are not only those caused by the necessity of finding out what areas are capable of economically producing commercial timber, but also those caused by the fluctuating demand for unoccupied lands for settlement. Many genuine applicants have little knowledge of how to select their prospective farms. Intending settlers, especially those from the fertile Prairies, often assume that any fairly level land is suitable for the plow after it has been cleared of timber or brush. They find it difficult to recognize the fact that a large proportion of our soils have physical or chemical characteristics which make them unsuitable for farming, or that in many parts irrigation is essential. To add to the difficulties in dealing with settlers, a great deal of the demand for free homesteads is not now for the purpose of creating real farms, but for temporary homes, for cheap pasture, for free timber, or other purposes quite often less profitable than commercial timber production. "I am not a farmer, but I can borrow some tools and a horse, and I want to live nearer the school for my children". . . "I have no capital, but I want to make a home on this place to avoid going on relief" . . : "This land is not suitable for plowing, but I want to use it for rough pasture for my cows." These are actual reasons given with applications to pre-empt land on which successful farming would be quite impossible. The number of such demands fluctuates as the opportunities for employment in other industries are favourable or otherwise. The indecisions of nature in the definition of forests is at least equalled by the indecisions of man as to their use.

There is evidence that the unoccupied land suitable for agricultural development and within reach of existing communities has become scarce, and that, even including the effects of the present industrial depression, there is less desire to settle in unfavourable locations than formerly. The number of pre-emption records allowed annually in British Columbia (excluding the Peace River land) has decreased from an average of 3,290 for the five years 1910-1914 to an average of 466 for the five years 1927-1931, and the number of pre-emptors who completed their statutory improvements from 748 to 164. The average total acreage of Crown land deeded annually has decreased from 342,700 acres to 77,400 acres for the same periods. Of the latter, 30,810 acres were Crown grants of pre-empted land. These figures indicate that the free farm land has gone and that the demand for forest land for inappropriate purposes is becoming of minor importance. The time is opportune for permanent definition of forest boundaries. 
While nature has not fenced our forests for us, she has been of great assistance in the matter by indicating in most parts of the province approximately where the boundaries will be found. The agricultural land usually lies in river valleys and on the lower benches; it is such a small proportion of the total land area, probably less than $6 \%$, and the forest land so extensive, probably about $40 \%$, that conflict between the two uses is unnecessary, for the present at least. If land is suitable for agricultural development we do not include it in a Provincial Forest, even though it has not yet been cleared of timber. This topographic assistance usually reduces the work of detailed land classification to an examination of a fairly narrow strip on the river and lake benches. The importance of this feature in forest policy is great, because if there was a possibility of either agriculture or forestry for every acre and it was necessary to determine the comparative values of the two, it is probable that the expense involved would prevent the establishment of any permanent Forests on a large scale at the present time.

Another natural factor (assisted unconsciously by man) which reduces the difficulty of locating forest boundaries is fire. Fire, next to rainfall, probably has more influence on the character and distribution of forests than any other agent. In the interior of the province, especially the southern part, for many years fires have been defining the areas on which the risk of loss by fire is low enough for the successful practice of forestry. The loss of large tracts of what was once productive forest land is regrettable, but it is one of the unavoidable results of civilization that fire hazards are greatly increased until a balance is struck and the forest has adjusted itself to changed conditions. That this process is well on its way is evidenced by the fact that in the Southern Interior Forest District the annual loss by fire of merchantable timber and young growth during the last fourteen years has been reduced to 71,300 acres, a large area, but only $1.2 \%$ of the productive forest land, stocked and unstocked. Fires on sites not capable of producing timber, whether these have always been unproductive or have been made so by previous fires, are of no further significance in forestry except as a sanitary agent cleaning the boundaries of the areas which can be maintained as per. manent forests.

Though the limits of a proposed Provincial Forest have been roughly indicated by the above factors, there still remains the classification of a strip of border lands so that the definite boundaries may be decided upon. This is done by a field survey of all lands which may appear to have any agricultural or other possibilities. Examination strips are run and the soil examined at regular intervals of five chains. Surveyed lands are reported upon by individual quarter sections. The possibilities for development are investigated with respect to character of soil, extent of good land, need for irriga- 
tion, nature of crops which could be grown, distance from settlements and markets, cost of clearing. Isolated patches of good land, areas at high elevations or with climatic conditions unsuitable for farming, dry soils for which no irrigation is possible, are not recommended for settlement and are included within the forest boundaries if they have any value for growing timber.

This work has been carried on for seven years and permanent boundaries have been located for existing forests and proposed forests totalling nearly ten million acres. About 300,000 acres have been classified on agricultural value, including physical classification and mapping of soils. This work, in addition to locating forest boundaries, has been of great assistance in the direction of settlement from unsuitable lands to areas which are capable of agricultural development and have been placed outside the forest boundaries. Some of these boundaries have been fixed for several years and little difficulty has been experienced in maintaining them against applicants with purposes inimical to forestry, while there has been an increasing demand within the forests for special uses peculiar to forest administration such as permits for hay cutting, fishing and hunting cabins and summer homes. British Columbia has not yet reached the stage of expecting its forests to be fenced, but they have certainly come to be regarded more in the nature of valuable State property than anybody's practically useless land. Whatever may be thought of the selfishness of the age with regard to the preservation of its inherited natural resources, British Columbia can take credit at least for a realization of its responsibilities and for the beginning of a policy designed to hand on its forest properties in a producing condition. It is building up these properties in definite units capable of individual attention and is adding to them as its circumstances will allow. It is not content with attempting a general administration of the whole country with respect to forestry in the hope that the forests will somehow remain in a satisfactory condition, both standing timber and future yield.

In brief-

The demand for settling forest land in the organized parts of British Columbia has diminished to insignificant proportions, and the time is opportune for fixing permanent forest boundaries.

Nature has assisted materially by placing topographic and soil limits for agricultural development.

Forest fires have been, and are still, serving to indicate areas that will prove unprofitable for forestry on account of the excessive costs of protection.

Forest boundary land classification work has been done for seven years and suitable permanent boundaries for almost ten million acres of forests have been located.

A capacity of 355 million board feet sustained annual yield, in the present 
condition of their growing stock, has been ascertained to be available from Provincial Forests already demarked. This is only about one-eighth of the total normal utilization of the province and much of it is a lower grade of material than that now cut.

The policy of creating Provincial Forests for perpetual production of timber has as its aim the supply of raw material for all forest industries on a regulated and sustained basis.

The policy of creating definite permanent boundaries for the Forests is designed ultimately to enable a concentration of all forest activities within these boundaries and a consequent increased efficiency in forest protection and general administration.

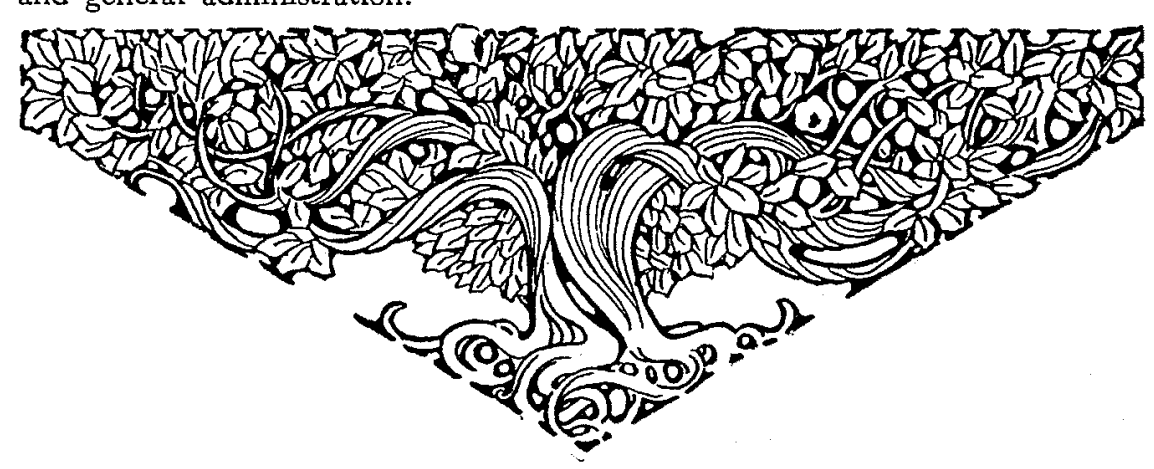

